\title{
Efficacy of a recombinant single-chain fragment variable region, VasSF, as a new drug for vasculitis
}

This article was published in the following Dove Medical Press journal:

Drug Design, Development and Therapy

\author{
Yosuke Kameoka' \\ Fukuko Kishi' \\ Minako Koura ${ }^{2}$ \\ Yoshio Yamakawa' \\ Rora Nagasawa' \\ Fuyu Ito ${ }^{3}$ \\ Junichiro Matsuda ${ }^{2}$ \\ Osamu Suzuki ${ }^{2}$ \\ Toshinori Nakayama ${ }^{4}$ \\ Kazuo Suzuki ${ }^{1,3-5}$ \\ 'Department of Research and \\ Development, A-CLIP Institute, Ltd., \\ Chiba, Japan; ${ }^{2}$ Laboratory of Animal \\ Models for Human Diseases, National \\ Institutes of Biomedical Innovation, \\ Health and Nutrition, Osaka, Japan; \\ ${ }^{3}$ Asia International Institute of \\ Infectious Disease Control, Teikyo \\ University, Tokyo, Japan; ${ }^{4}$ Department \\ of Immunology, Graduate School of \\ Medicine, Chiba University, Chiba, \\ Japan; ${ }^{5}$ Department of Immunology, \\ National Institute of Infectious \\ Diseases, Tokyo, Japan
}

Correspondence: Yosuke Kameoka Department of Research and Development, A-CLIP Institute, Ltd., Inohana I-8-15, Chyuoku, Chiba City, Chiba 260-0856, Japan

$\mathrm{Tel}+8|4322| 083 \mid$

Fax +81432210832

Email office@a-clip.jp
Background: Anti-neutrophil cytoplasmic autoantibodies (ANCA) associated vasculitis is a pauci-immune disease with the inflammation of the small blood vessels. The efficacies of antibody drugs for induction therapies of vasculitis vary among cases. Here, we developed a novel clone of a single chain $\mathrm{Fv}$ region $(\mathrm{ScFv})$ with vasculitis-specific therapeutic potential.

Materials and methods: The clone, termed VasSF, was selected from our Escherichia coli expression library of recombinant human $\mathrm{ScFv}$ based on the therapeutic efficacy in an SCG/ $\mathrm{Kj}$ mouse model of MPO-ANCA-associated vasculitis (MAAV), such as improvement of the urinary score and decreased crescent formation in glomeruli, granulomatous in lung, MPOANCA biomarkers, the anti-moesin antibody, and some cytokine levels.

Results: We identified vasculitis-associated apolipoprotein A-II (VAP2) as a target molecule of the clone and confirmed the independently-established VAP2 antibodies were also therapeutic in SCG/Kj mice. In MAAV, MPO-ANCA and cytokines stimulate neutrophils by facilitating heterodimer formation of VAP2 with apolipoprotein A-I in HDL.

Conclusion: VasSF would constitute a novel antibody drug for vasculitis by suppressing the heterodimer formation of the apolipoproteins.

Keywords: VasSF, ANCA antibody drug, apolipoprotein, HDL, myeloperoxidase, MPO, $\mathrm{SCG} / \mathrm{Kj}$, vasculitis

\section{Introduction}

Anti-neutrophil cytoplasmic autoantibodies (ANCA)-associated vasculitis, including anti-myeloperoxidase antibody (MPO-ANCA) and anti-proteinase 3 antibody (PR3-ANCA), might be caused by the injury of the blood vessels from the dysregulation of the activated neutrophils. ${ }^{1}$ Vasculitis includes inflammation of various types of blood vessels. Patients with vasculitis show a wide variety of inflammatory signs in blood vessels of particular sizes. Guidelines for the treatment of vasculitis vary among Europe, the USA, and Japan in terms of the method to suppress inflammation. The European League against Rheumatism, the European Renal Association-European Dialysis and Transplant Association (ERA-EDTA), and the European Vasculitis Society, involving experts worldwide, reported a validation study for treating the induction of remission of ANCA-associated vasculitis and disease management. Immunosuppressive medications, such as cyclophosphamide and azathioprine, were recommended by almost all experts, and the combination with antibody drugs, eg, rituximab targeting CD20-positive cells, is also recommended for the treatment of granulomatosis with polyangiitis/microscopic polyangiitis. ${ }^{2,3}$ In Japan, the guidelines for treating severe vasculitis recommend steroids, immunosuppressive therapy, and antibody drugs, such as rituximab. ${ }^{3-5}$ 
However, these therapies can cause severe infections in elderly patients with severe vasculitis. In addition, although antibody drugs likely work by binding to and neutralizing target antigens, ${ }^{6}$ it remains unclear how these drugs work in patients with severe vasculitis. Nevertheless, the efficacy of these antibodies suggests that vasculitis might be particularly treatable with therapeutic antibodies designed to target key molecules in the vasculitis pathway. Thus, antibody drugs for vasculitis treatment need to be developed based on a specific target molecule(s) as materials involved in the etiological mechanism of the disease. To improve therapeutic efficacy for MPO-ANCA-associated vasculitis (MAAV), we focused on the gamma globulin population in human blood because the administration of a large amount of intravenous gamma globulin (IVIg) is reportedly effective for treating patients with vasculitis. ${ }^{7-9}$ Although the effect of IVIg has been pointed out to be an immunomodulatory effect via Fc gamma (Fcy) receptor, its therapeutic mechanism is not completely clarified. ${ }^{10}$ As Fc and sugar moieties of IgG can cause neutrophils activation via the Fc $\gamma$ receptors, ${ }^{11,12}$ we have established a library of human, recombinant IgG, single-chain Fv regions (hScFv). ${ }^{13}$

Here, we developed a recombinant clone for a vasculitisassociated antibody drug by screening an $\mathrm{hScFv}$ library consisting of 204 clones based on the therapeutic activity in $\mathrm{SCG} / \mathrm{Kj}$ mice $^{13}$ that spontaneously develop vasculitis. The most effective clone was chosen for further study. The antibody's target molecule was identified by mass spectrometry (MS), and using the polyclonal antibodies its effectiveness was verified in SCG/Kj mice. ${ }^{14}$ Our findings will not only be useful for developing new antibody drugs for remission of MAAV, but also for understanding the etiology of vasculitis.

\section{Materials and methods}

\section{Construction and screening of the recombinant hScFv library}

Antibody fragments with a therapeutic benefit for vasculitis were selected from a human $\mathrm{ScFv}$ expression library containing $204 \mathrm{VH}-\mathrm{CH} 1$-hinge regions. ${ }^{13}$ The clones were classified according to the number of occurrences of identical $\mathrm{VH}$ region sequences in the library. Clones were grouped depending on the copy number of the same amino acid sequences of the $\mathrm{VH}$ regions, namely, four of the same clone (Group 1: Gr-1), three of the same clone (Group 2: Gr-2), and two of the same clone (Group 3: Gr-3). Unique clones were randomly selected (Group 4: Gr-4) (Figure S1).

\section{Reconstruction and optimization of the insert}

The most therapeutically effective clone, a Gr-1 Rq01 subclone, was sequenced, and the coding region was reconstructed for optimal expression in Escherichia coli. This reconstructed Rq01 (which we will refer to as URq01) was inserted into the pET-32a vector and transfected to BL21(DE3) competent cells. The sequence of the hScFvexpressing clone was confirmed via the vector construct (Figure S2A and B).

\section{Purification of recombinant clone proteins}

The recombinant URq01 (Gr-1) protein was induced with IPTG $(0.1 \mathrm{M})$ overnight at $16^{\circ} \mathrm{C}$ and the cell pellets were harvested and frozen. The pellets were suspended in a $20 \mathrm{~mL} / \mathrm{L}$ culture of $50 \mathrm{mM}$ Tris ( $\mathrm{pH} 8.0$ ) containing $6 \mathrm{M}$ guanidine thiocyanate, and sonicated at $20 \mathrm{kHz}$ for 1 minute on ice with a VP-050 (TITEC, Gunma, Japan). The protein was purified from the extracts by affinity chromatography on a Ni-Sepharose 6 Fast Flow (GE Healthcare, Buckinghamshire, UK) column $(2.5 \times 8.0 \mathrm{~cm})$ with $8 \mathrm{M}$ urea, $0.3 \mathrm{M} \mathrm{NaCl}$, and $50 \mathrm{mM}$ Tris $(\mathrm{pH} \mathrm{8.0)}$ ). The proteins were eluted with $0.1 \mathrm{M}$ EDTA, $8 \mathrm{M}$ urea, $0.3 \mathrm{M} \mathrm{NaCl}$, and $50 \mathrm{mM}$ Tris (pH 8.0). The proteins were purified by gel filtration (high-performance liquid chromatography) on Shodex KW-802.5 $(0.8 \times 30 \mathrm{~cm})$ and $803(0.8 \times 30 \mathrm{~cm}$; SHOWA DENKO K.K., Tokyo, Japan $)$ columns and gel-filtration column chromatography with $8 \mathrm{M}$ urea in PBS. The proteins were further purified by a $\left(\right.$ TSKgel $\left.^{\circledR}\right)$ DEAE-5PW column $(0.75 \times 7.5 \mathrm{~cm}$; TOSOH, Tokyo, Japan $)$, and by cobalt-coordinate Sepharose 6 Fast Flow. The protein was concentrated and applied to gel filtration to exchange the $6 \mathrm{M}$ guanidine in the PBS (Figure $\mathrm{S} 2 \mathrm{C}-\mathrm{E}$ ). The $\mathrm{hScFv}$ was renatured by removing the guanidine by dialysis with PBS containing $0.8 \mathrm{M}$ arginine and subsequent dialysis with PBS only.

\section{Evaluation of therapeutic effects in a mouse model}

All animal experiments followed the guidelines from the National Institutes of Biomedical Innovation, Health, and Nutrition, Osaka, Japan (authorization number: DS21-8). Therapeutic effects were evaluated using $\mathrm{SCG} / \mathrm{Kj}$ mice as the MAAV mouse model. ${ }^{14}$ In the treatment group, 10-week-old mice were treated daily for 5 days with intraperitoneal injections of $0.4 \mathrm{mg} / \mathrm{kg}$ of samples dissolved in PBS-containing stabilizers ( $1.5 \% \mathrm{D}$-mannitol and $0.45 \%$ glycine). Mice in the control group were administered solvent only. The numbers of mice in experimental groups were 6, 4, 3, 3, 3, 3, 4, and 4 in 
C57BL/6, solvent, G1LQq, G1hEq, G2Lt, VasSF, hIgG, and vasculitis-associated apolipoprotein A-II (VAP2), respectively. The animals were euthanized by $\mathrm{CO}_{2} 3$ weeks later.

\section{Effect of treatment on the SCG/Kj mice}

Urinary scores ranging from 0 to 7 were sums of the urinary protein and occult blood scores measured by the Uropaper III Eiken E-UR42 (Eiken Chemical Co. Ltd., Tokyo, Japan). The urinary protein scores were as follow: 0 , if urinary protein concentration measured by a protein error of $\mathrm{pH}$ indicators ${ }^{15}<30 \mathrm{mg} / \mathrm{dL}$; 1 , if $30-100 \mathrm{mg} / \mathrm{dL} ; 2$, if $100-300 \mathrm{mg} / \mathrm{dL}$; 3 , if $300-1,000 \mathrm{mg} / \mathrm{dL}$; and 4 , if $>1,000 \mathrm{mg} / \mathrm{dL}$. Note that a considerable amount of urinary protein $(20-30 \mathrm{mg} / \mathrm{dL})$ is usually detected even in normal mice because of the presence of major urinary proteins. ${ }^{16}$ The occult blood levels were classified from 0 (not detected) to 3 (high concentration). The crescent formation rate (\% crescents) was determined with $80-100$ glomeruli on a hematoxylin and eosin-stained slide of kidney tissues. Blood counts of white blood cells, lymphocytes, monocytes, and granulocytes were measured with a VetScan HMII auto analyzer (ABAXIS, Union City, CA, USA). The serum levels of biomarkers, MPO-ANCA, and anti-moesin antibodies ${ }^{17,18}$ were measured by enzyme-linked immunosorbent assay. The values of MPO-ANCA titer was shown as the equivalent of the standard mouse MPO-ANCA serum IgG. Multiplex immunoassays (Bio-Plex; Bio-Rad, Hercules, CA, USA) were used to measure serum levels of 23 inflammatory cytokines/chemokines, ${ }^{17}$ that is, interleukin (IL)-1 $\alpha$, IL-1 $\beta$, IL-2, IL-3, IL-4, IL-5, IL-6, IL-9, IL-10, IL-12p40, IL-12p70, IL-13, IL-17, eotaxin, granulocyte colony-stimulating factor, granulocyte macrophage-colony stimulating factor, interferon (IFN)- $\gamma$, keratinocyte-derived chemokine, monocyte chemoattractant protein-1, macrophage inflammatory protein (MIP) $-1 \alpha$, MIP-1 $\beta$, regulated on activation, normal $\mathrm{T}$ cell expressed and secreted, and tumor necrosis factor- $\alpha$ (TNF- $\alpha$ ).

\section{Determination of the target molecules}

We selected the most effective clone, named VasSF (vasculitis-associated $\mathrm{ScFv}$ ), to identify its target molecule(s) by affinity purification followed by MS. One milligram of VasSF was applied to $25 \mathrm{mg}$ of Dynabeads Tosylactivated (Thermo Fisher Scientific, Waltham, MA, USA) in $0.1 \mathrm{M}$ sodium borate buffer, $\mathrm{pH}$ 9.5. The VasSF-bound beads were washed five times with PBS containing $0.05 \%$ Tween 20 . Three milliliters of plasma from healthy volunteers was diluted 10-fold with PBS and incubated with $25 \mathrm{mg}$ of the beads with rotation for 1 hour at room temperature. The bound proteins were eluted with $0.1 \mathrm{M}$ glycine- $\mathrm{HCl}$, $\mathrm{pH} 2.7$, and the eluate was neutralized by adding 1:10 vol of $1 \mathrm{M}$ TrisHCl, $\mathrm{pH}$ 9.0. Then, the eluted proteins were separated by sodium dodecyl sulfate-polyacrylamide gel electrophoresis. The gel region was visualized by silver staining and was excised. The bound peptide fragments were released from the excised piece of gel by digestion with protease. The peptide fragments were subjected to MS. Tandem mass spectroscopy (MS/MS) spectra were obtained by selecting ions from specific peptides in the mass spectrometer. Five milligrams of VAP2-conjugated beads were prepared as described above. The beads were mixed with $3 \mathrm{~mL}$ of the VasSF solution and washed seven times. The bound proteins were eluted and detected by Western blotting with the anti-human IgGF (ab') 2 antibody (609-4118, Rockland Immunochemicals Inc., Limerick, PA, USA).

\section{Statistical analyses}

The urinary scores were statistically analyzed with the Kruskal-Wallis analysis of variance by ranks, followed by Dunn's method using SigmaPlot version 14 (Systat Software Inc., San Jose, CA, USA). The other observed values were statistically analyzed with analysis of variance, followed by Tukey's test if normality and equal variance were confirmed by the Shapiro-Wilk and Brown-Forsythe tests, respectively. Otherwise, statistical analyses were performed using the Kruskal-Wallis one-way analysis of variance by ranks, followed by Dunn's test. A $P$-value $<0.05$ was considered significant. The observed values that showed the normal distribution were described as the mean $\pm \mathrm{SD}$, otherwise described as the median ( $\min -\max )$.

\section{Results \\ Selection of a clone from the hScFv 204-clone library}

The selected clone groups were divided into four groups: Gr-1, Gr-2, Gr-3, and Gr-4 (Figure S1). The sequence encoding VasSF was subcloned to optimize expression in E. coli. One Gr-1 clone (subclones Rq01, G1LQq, G1Qq, and G1hEq) was selected based on the therapeutic efficacy of the purified protein injected into $\mathrm{SCG} / \mathrm{Kj}$ mice. Efficacy was based on 1) urinary score (Figure 1A), 2) crescent formation in glomeruli (Figure 1B), 3) spleen weight/body weight (Figure 1C), 4) histological status of the kidney and spleen (not shown), and 5) serum levels of biomarkers such as MPO-ANCA (Figure 1D), TNF- $\alpha$ (Figure 1E), and anti-moesin antibody (Figure 1F). 
A

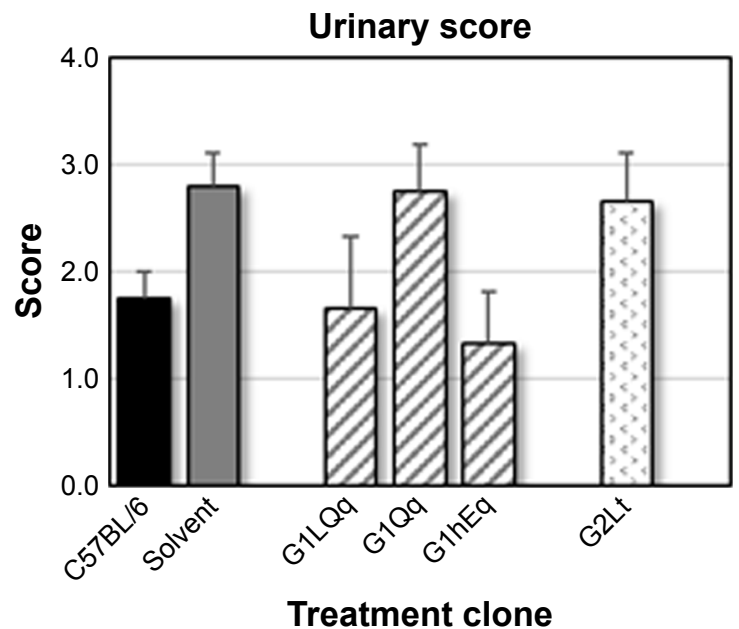

C

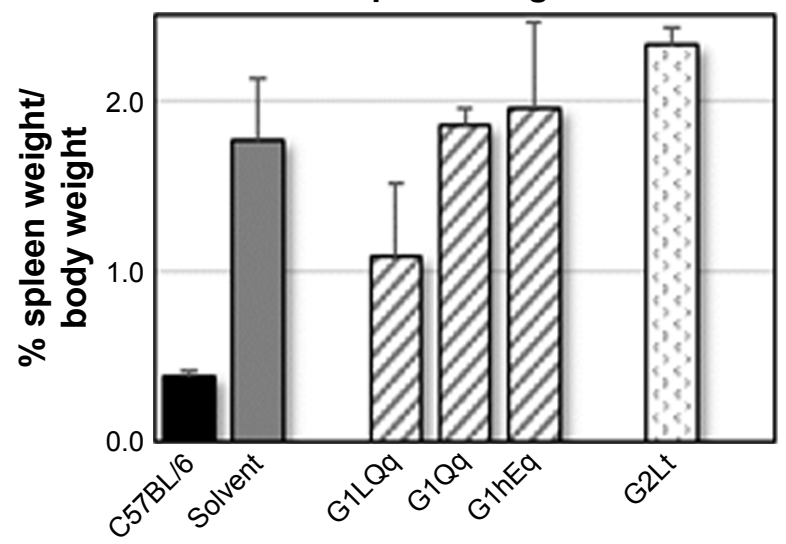

Treatment clone

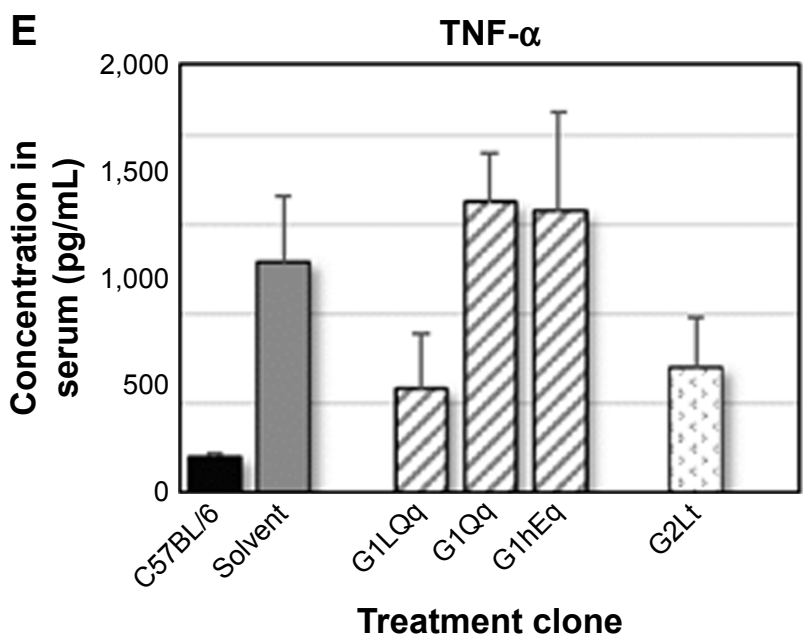

B
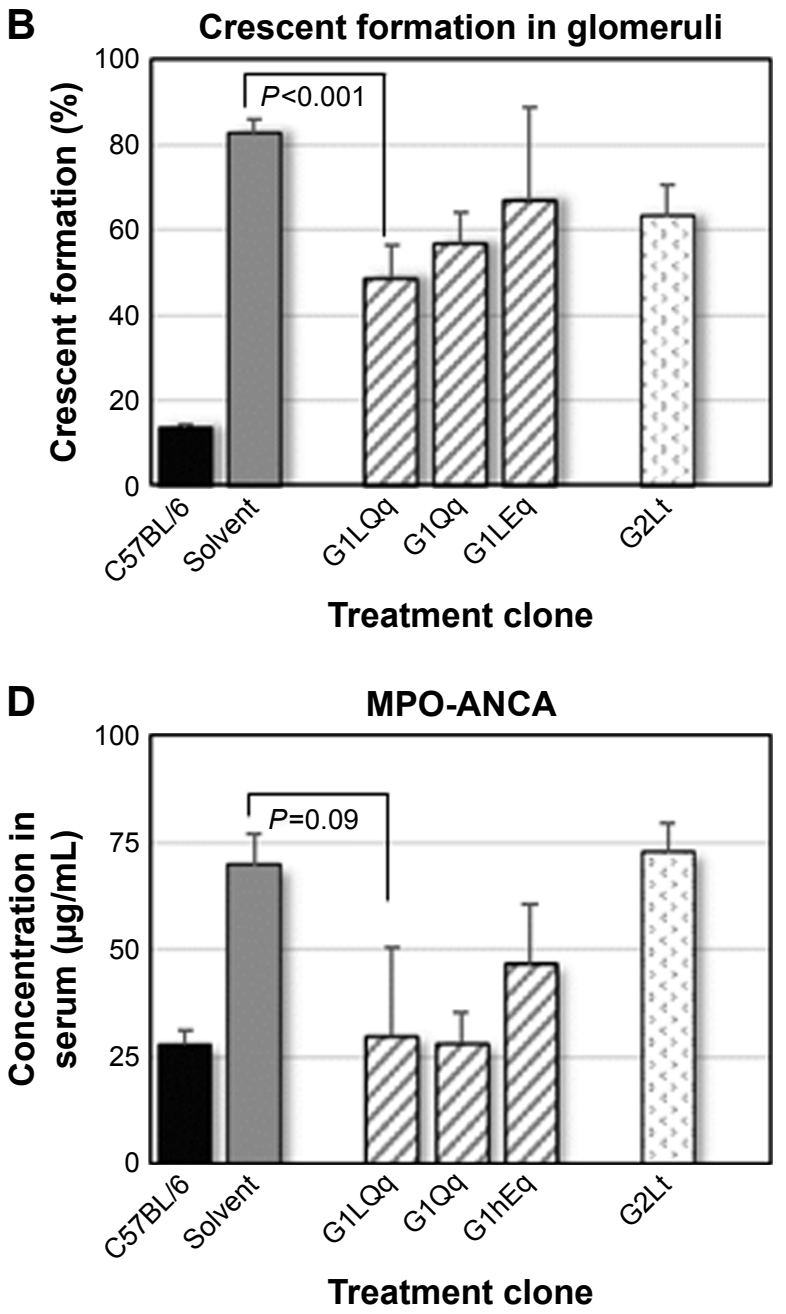

F

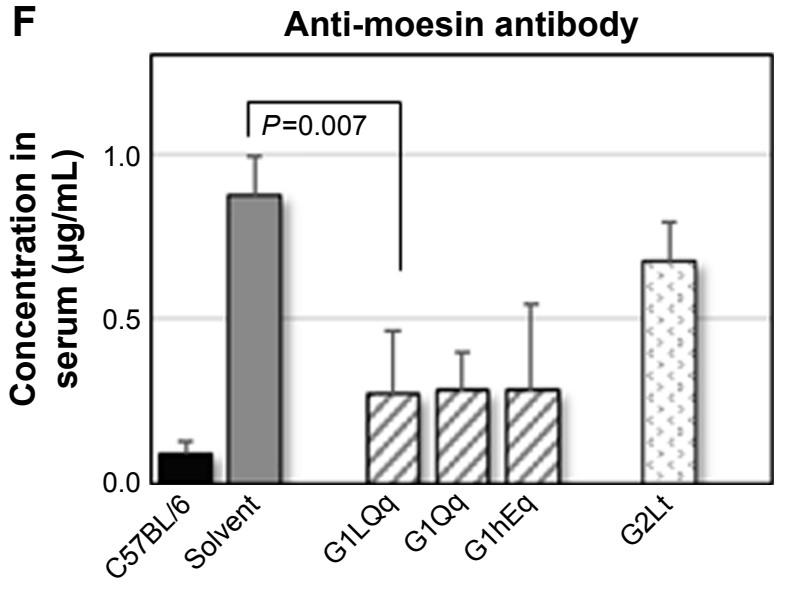

Treatment clone

Figure I Selection of the therapeutic hScFv clone from the 204-clone library.

Note: Evaluation criteria were the urinary score (A), crescent formation (B), spleen weight/body weight (C), serum biomarker levels of MPO-ANCA (D), TNF- $\alpha$ (E), and an antibody to moesin (anti-moesin, F).

Abbreviations: hScFv, human single-chain Fv regions; MPO-ANCA, myeloperoxidase anti-neutrophil cytoplasmic autoantibodies; TNF- $\alpha$, tumor necrosis factor- $\alpha$.

VasSF injections had a therapeutic effect on kidney and immune functions

Significantly more glomerular crescent formation was observed in $\mathrm{SCG} / \mathrm{Kj}$ mice administered control samples (ie, "solvent") than that of the healthy control C57BL/6 mice, but VasSF treatment reversed a variety of these disease manifestations in mice compared with those in mice in the "solvent" control group: the crescent formation recovery value 

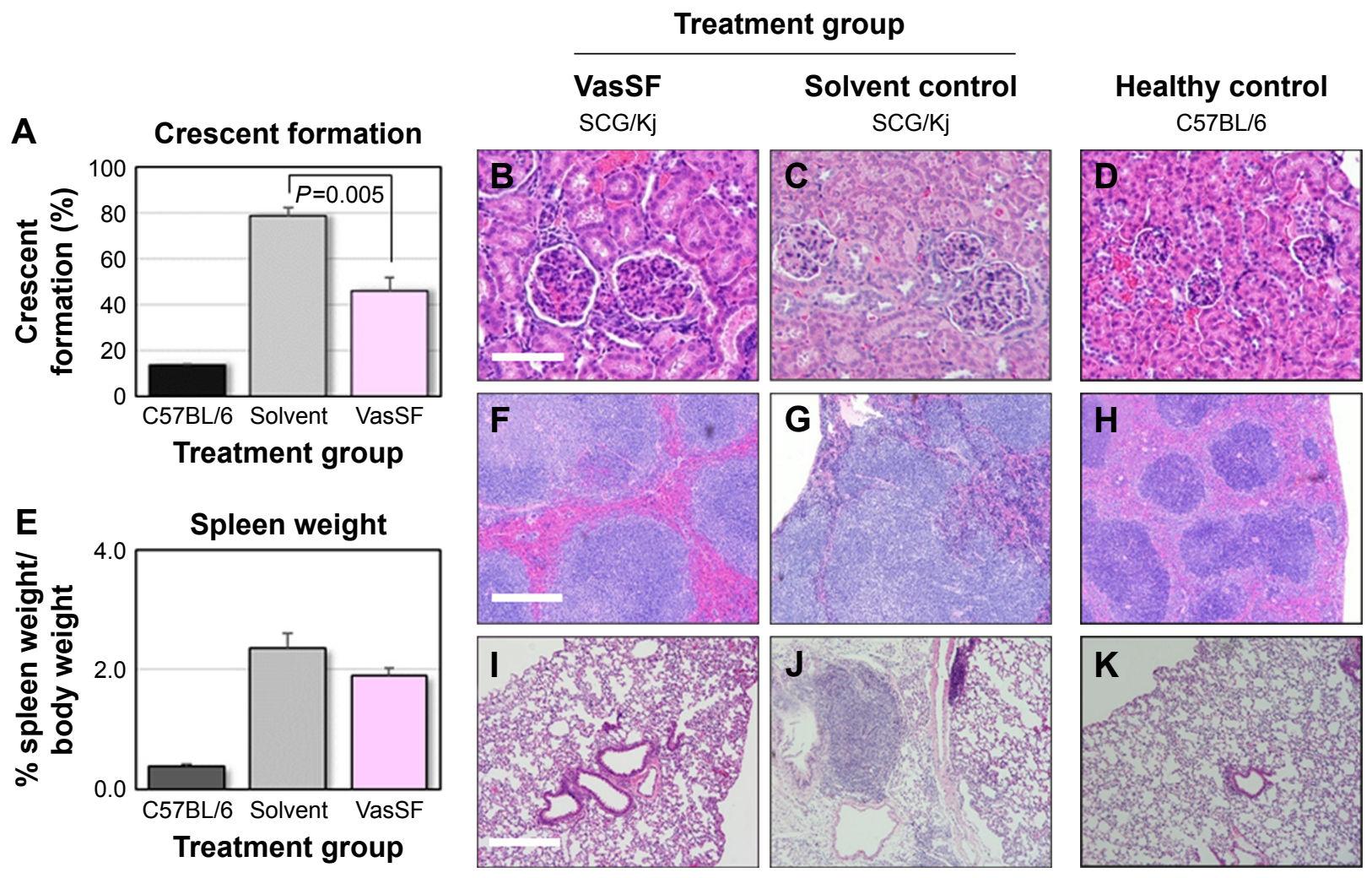

Figure 2 Therapeutic effects of VasSF on kidney, spleen, and lung.

Notes: Percentage crescent formation in glomeruli. (A) Microscopic analysis of a kidney in an SCG/Kj model mouse after administration of the purified recombinant VasSF therapeutic (B), the solvent control (C), or a representative healthy C57BL/6 mouse. (D) Spleen weight ratio. (E) Microscopic analysis of spleen in an SCG/Kj model mouse after administration of the purified recombinant VasSF therapeutic (F), the solvent control $(\mathbf{G})$, or a representative healthy C57BL/6 mouse $(\mathbf{H})$. Microscopic analysis of a lung in an SCG/Kj model mouse after administration of the purified recombinant VasSF therapeutic (I), the solvent control (J), or a representative healthy C57BL/6 mouse (K). Bar: $100 \mu \mathrm{m}$.

Abbreviation: VasSF, vasculitis-associated ScFv.

was $46.1 \% \pm 11.3 \%$ from $78.5 \% \pm 10.2 \%$ (Tukey, $P=0.005$ ) in "solvent" (Figure 2A). The microscopic observations of the VasSF treatment showed recovery of glomeruli (Figure 2B) compared with that for the solvent control (Figure 2C) as well as healthy control (Figure 2D). In addition, spleen weight/body weight was $1.85 \%(1.64 \%-2.24 \%)$ from $2.36 \%$ $(1.64 \%-3.13 \%)$ (Dunn, $P=1.00)$ in solvent (Figure 2E), and microscopic separations of spleen white and red pulp clear separated the VasSF treatment (Figure 2F) from the solvent (Figure 2G) as shown in the healthy control (Figure 2H). Moreover, microscopic observations of lungs showed that VasSF treatment recovered normal lungs (Figure 2I) from those in the "solvent" control (Figure 2J), as shown in the C57BL/6 healthy control (Figure 2K).

Furthermore, animals given the VasSF therapy showed improved serum biomarker profiles in comparison with those in the control group: MPO-ANCA $(37.7 \pm 11.2$ vs $61.3 \pm 19.2 \mu \mathrm{g} / \mathrm{mL}$; Tukey, $P=0.168$; Figure $3 \mathrm{~A}$ ), antimoesin antibody $(0.13 \pm 0.25$ vs $0.75 \pm 0.33 \mu \mathrm{g} / \mathrm{mL}$; Tukey, $P=0.011$; Figure 3B), and TNF- $\alpha$ (491 [168-887] vs 1,360 [489-2,435] pg/mL; Dunn, $P=0.652$; Figure 3C).
Serum profiles of inflammatory cytokines/chemokines also improved, ie, IL-1ß: 386 (170-968) vs 3,829 (837-6,808) $\mathrm{pg} / \mathrm{mL}$, Dunn, $P=0.023$, Figure 3D; IL-5: 30.3 (14.7-82.7) vs $250(60.0-373) \mathrm{pg} / \mathrm{mL}$, Dunn, $P=0.028$, Figure 3E; IL-17: 42.3 (20.8-52.6) vs 170 (96.7-568) pg/mL, Dunn, $P=0.007$, Figure 3F; IFN- $\gamma$ : 27.7 (15.8-84.0) vs 1,007 (283-1,977) pg/mL, Dunn, $P=0.017$, Figure 3G; and MIP-1 $\beta$ : 73.4 (14.2115) vs 481 (218-695) pg/mL, Dunn, $P=0.008$, Figure $3 H$.

\section{Vasculitis-associated apolipoprotein A-II for the VasSF antigen/target molecule}

Affinity pull down with the Tosylactivated Dynabeads coated with VasSF isolated a clear band at $\sim 10 \mathrm{kDa}$ (red arrowhead in Figure 4A). The cutout piece of the gel was estimated to contain eleven candidate proteins including VAP2 registered in the database. In contrast, binding VasSF to VAP2 was confirmed by binding with VAP2-conjugated beads (Figure 4B). We also investigated the $25 \mathrm{kDa}$ band, which was apolipoprotein A-1 (AP1) according to the MS/MS analysis (Figure 4A, open arrowhead), showing VAP2 binding AP1 in serum. 
A
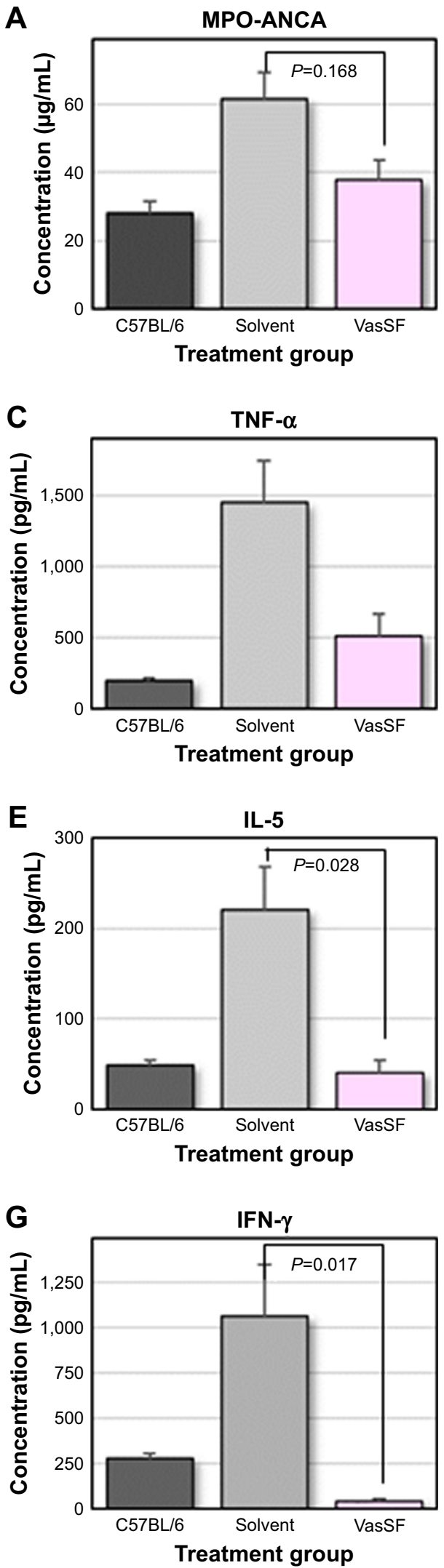

B
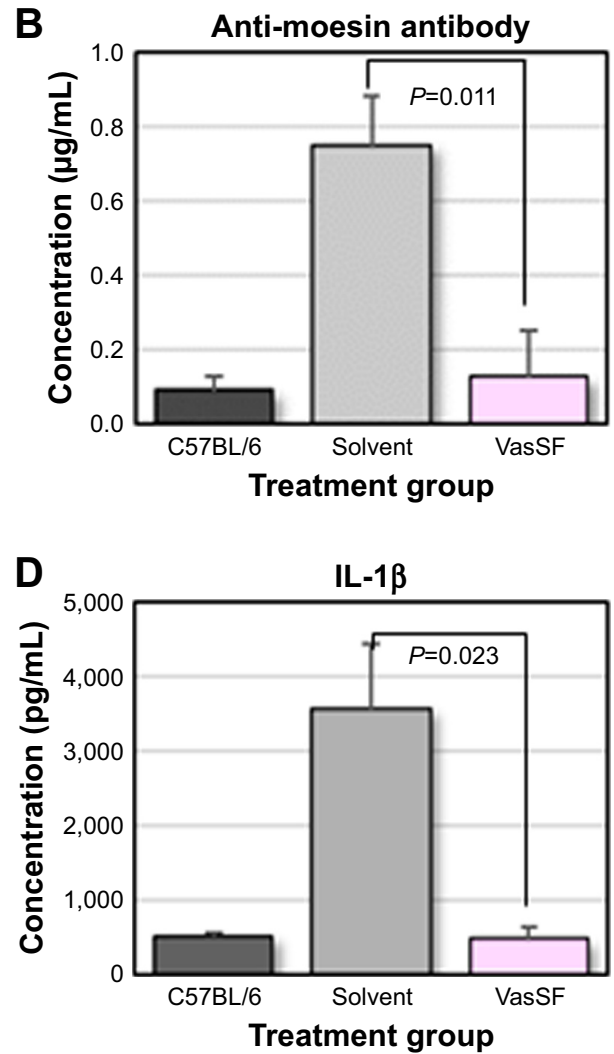

$\mathbf{F}$

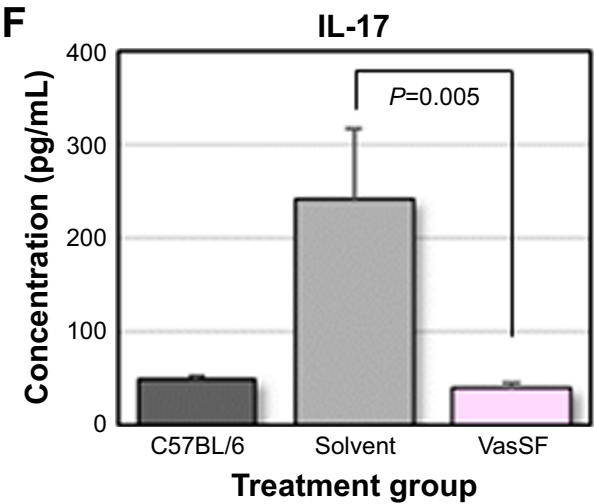

H

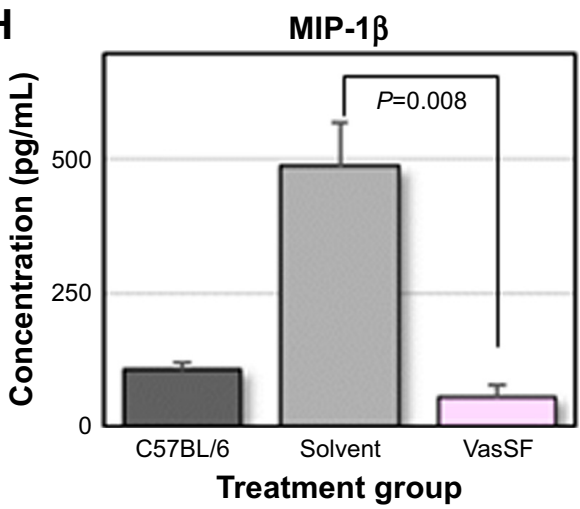

Figure 3 Therapeutic effects of VasSF on two biomarkers (MPO-ANCA and anti-moesin antibody), and cytokines/chemokines in serum.

Note: Biomarkers and cytokines/chemokines were measured in serum from healthy control (C57BL/6) and SCG/Kj mice treated with solvent only (solvent; control), and SCG/Kj mice treated with the purified recombinant VasSF therapeutic (VasSF): MPO-ANCA (A), anti-moesin antibody (B), TNF- $\alpha$ (C), IL-I $\beta$ (D), IL-5 (E), IL-I7 (F), IFN- $\gamma(\mathbf{G})$, and MIP-I $\beta(\mathbf{H})$.

Abbreviations: IFN, interferon; IL, interleukin; MIP, macrophage inflammatory protein; MPO-ANCA, myeloperoxidase anti-neutrophil cytoplasmic autoantibodies; TNF- $\alpha$, tumor necrosis factor- $\alpha$; VasSF, vasculitis-associated ScFv. 

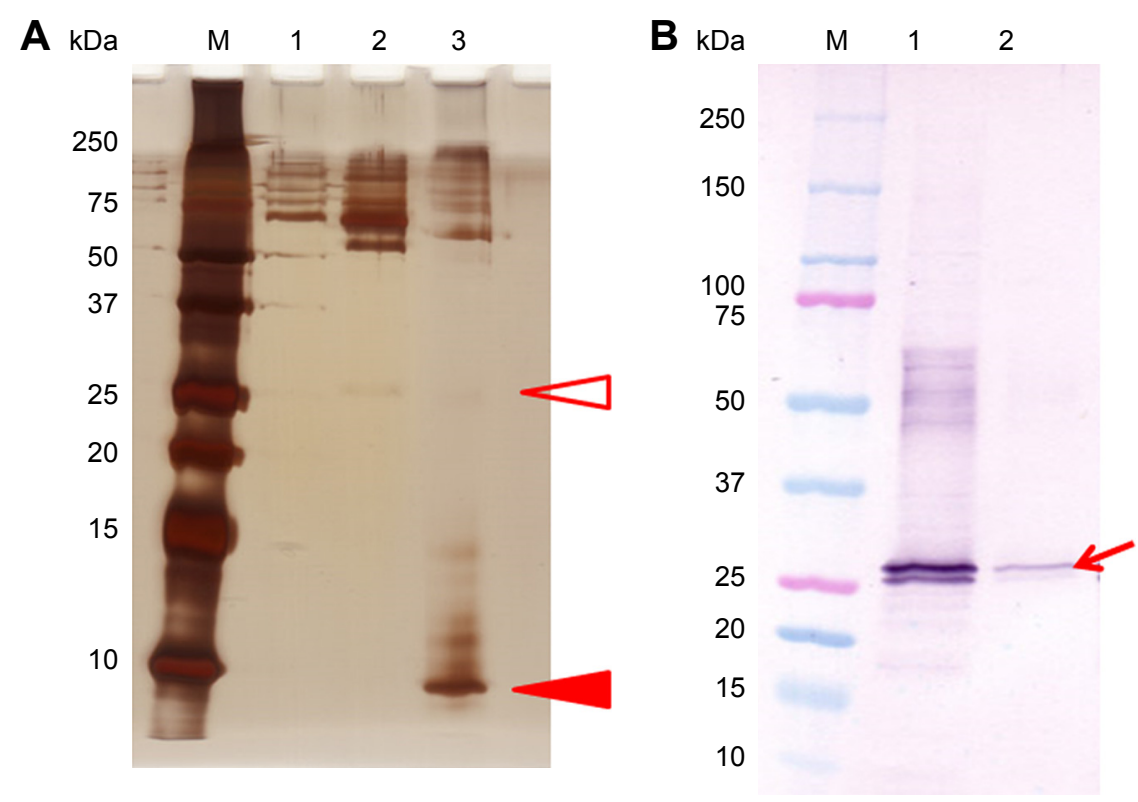

Figure 4 Identification of VasSF target molecules.

Notes: (A) SDS-PAGE with silver stain: lane M, molecular weight markers; lane I, plasma $50 \mathrm{kd}$ filter flow-through fraction; lane 2, unbound fraction of plasma exposed to VasSF beads; lane 3, eluate fraction of plasma bound to the VasSF beads. Red arrowheads, the portion of the gel cut out for MS/MS analysis. (B) Western blot detection (red arrow) with anti-Fab antibody of VasSF binding to VAP2-conjugated beads; lane M, molecular weight markers; lane I, VasSF solution before pull down by VAP2-conjugated beads; lane 2, fraction eluted from VAP2-conjugated beads.

Abbreviations: VAP2, vasculitis-associated apolipoprotein A-II; VasSF, vasculitis-associated ScFv.

We wanted to determine whether VAP2 is a VasSF antigen that binds VAP2 in human plasma in vitro. Therefore, anti-VAP2 polyclonal antibodies (aVAP2) were injected into $\mathrm{SCG} / \mathrm{Kj}$ mice to alleviate their vasculitis symptoms, such as glomerular crescent formation (from $78.5 \% \pm 5.1 \%$ to $56.3 \% \pm 6.3 \% ; P=0.078$; Figure $5 \mathrm{~A}$ ). The recovery of the glomerular crescent formation with the aVAP2 was also confirmed in histological observations of the aVAP2 treatment (Figure 5B) compared to the solvent (Figure 5C) and the hIgG (Figure 5D). Moreover, biomarkers and cytokines recovered by the VasSF treatment were also analyzed with the aVAP2. The following biomarkers were measured in aVAPtreated and solvent-control groups: MPO-ANCA (38.9 \pm 16.6 vs $61.3 \pm 19.2 \mu \mathrm{g} / \mathrm{mL}$; Tukey, $P=0.204$; Figure $5 \mathrm{E}$ ), antimoesin antibody $(0.11 \pm 0.22$ vs $0.75 \pm 0.32 \mu \mathrm{g} / \mathrm{mL}$; Tukey, $P=0.009$; Figure 5F), and TNF- $\alpha$ (374 [321-708] vs 1,360 [489-2,435] pg/mL; Dunn, $P=1.00$; Figure 5G). Serum levels of cytokines were measured: IL-1 $3634(556-728)$ vs 3,829 (837-6,808) pg/mL; Dunn, $P=0.168$; Figure 5H, IL-5 57.0 (28.5-69.9) vs 250 (60.0-373) pg/mL; Dunn $P=0.225$; Figure 5I, IL-17 74.1 (40.1-78.2) vs $170(96.7-568) \mathrm{pg} / \mathrm{mL}$; Dunn, $P=0.342$; Figure 5J, IFN- $\gamma 38.4(14.0-49.0)$ vs $1,007(283-1,977) \mathrm{pg} / \mathrm{mL}$; Dunn, $P=0.009$; Figure $5 \mathrm{~K}$ and MIP-1ß 76.5 (43.3-87.6) vs 481 (218-695) pg/mL; Dunn, $P=0.031$; Figure 5L. The number of peripheral blood lymphocytes and granulocytes did not change in the aVAP2administered mice: WBCs: $4.42(1.36-7.57) \times 10^{9}$ cells/L vs
$3.14(1.48-15.7) \times 10^{9}$ cells/L (Figure S3A). The number of granulocytes decreased: $0.15(0.05-1.04) \times 10^{9}$ cells/L vs 0.22 $(0.04-0.69) \times 10^{9}$ cells $/$ L (Figure S3B).

These results indicate that VasSF targeted VAP2, and that the effective dose of VasSF was 1:4,000 of IVIg. Furthermore, the high amino acid sequence homology between VasSF (clone URq01) and the anti-VAP2 mouse monoclonal antibody registered in the public database (Figure S4) also indicated that the VasSF target antigen was VAP2. The idiotype (antigen binding site) in the two VH domains showed homologous amino acid alignment in 18/48 and 14/29 in the structure of the heavy chain variable region.

\section{Discussion}

In this study, we isolated a novel therapeutic clone from a 204-clone hScFv library..$^{13}$ Our strategy for selection was quite unique from that used to develop other antibody drugs, which recognize etiological and pathogenic molecules, such as cytokines/chemokines and their receptors. Two popular new antibody drugs, infliximab, the efficacy of which has been reported, ${ }^{19}$ and rituximab, ${ }^{3-5,20,21}$ have been developed as humanized IgG antibodies containing the entire antibody structure. As $\mathrm{Fc}$ and sugar moieties could cause neutrophils activation via the Fc $\gamma$ receptor, ${ }^{11,12}$ we devised a strategy to eliminate these moieties, and selected a single clone from an ScFv fragment library of polyclonal IgGs. ${ }^{13}$ Our antibody fragment not only recognized a protein target, but was also effective for MAAV. ${ }^{13}$ 
A
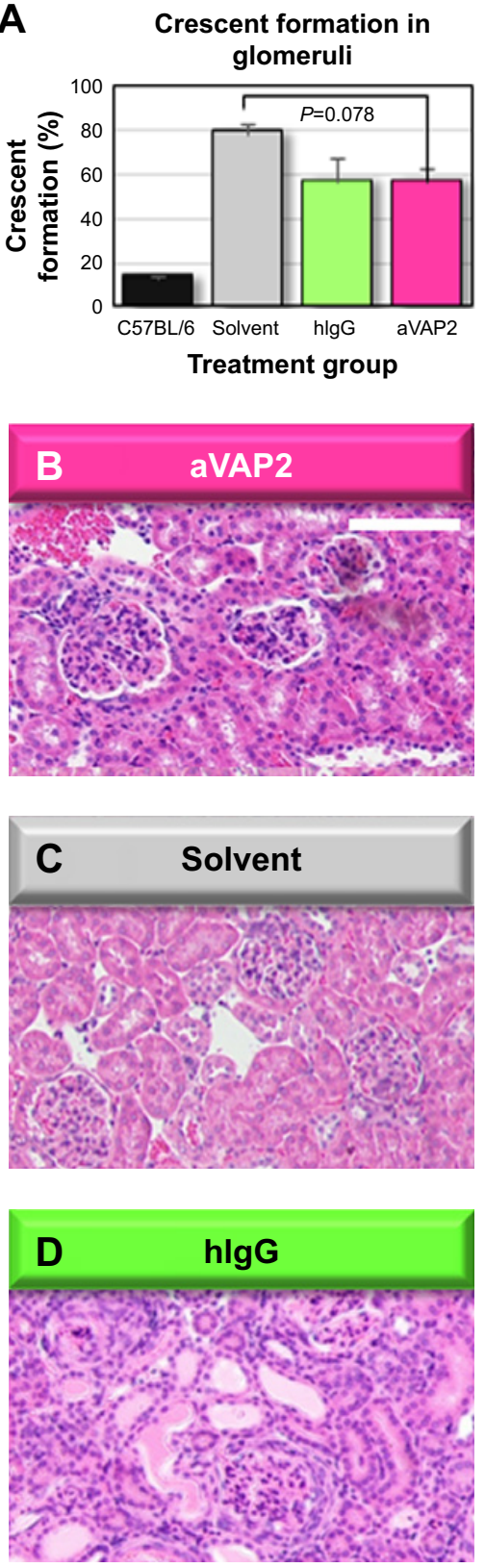

$\mathbf{E}$

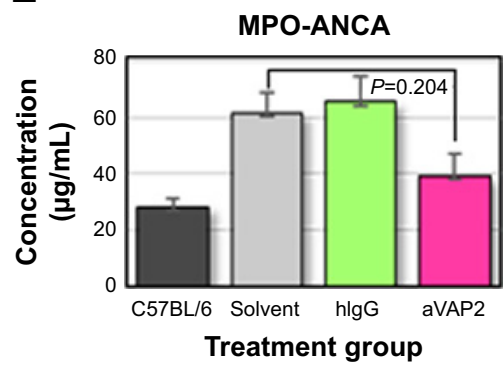

$\mathbf{G}$

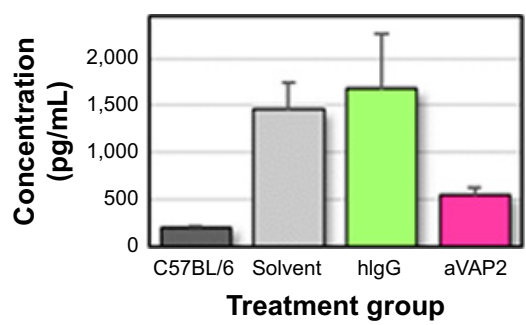

I

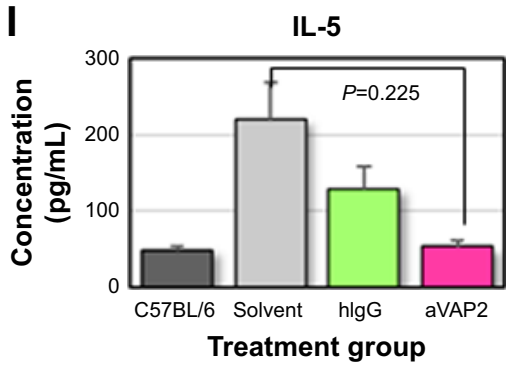

K

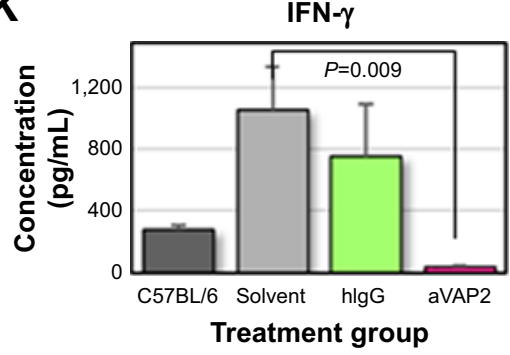

$\mathbf{F}$

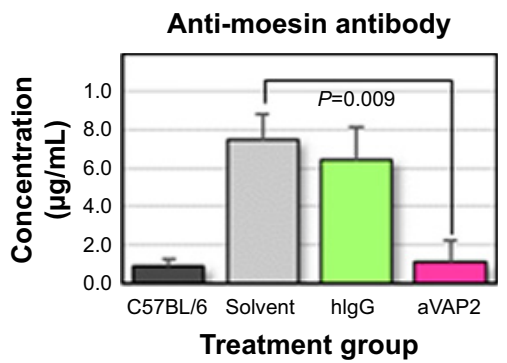

H

$1 \mathrm{~L}-1 \beta$

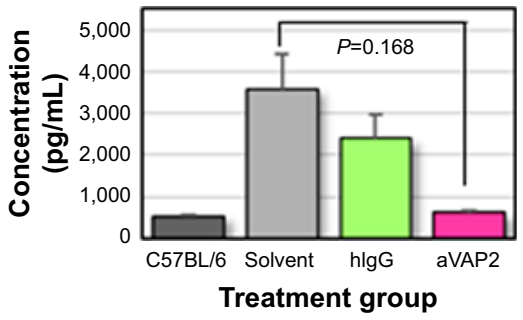

$\mathbf{J}$

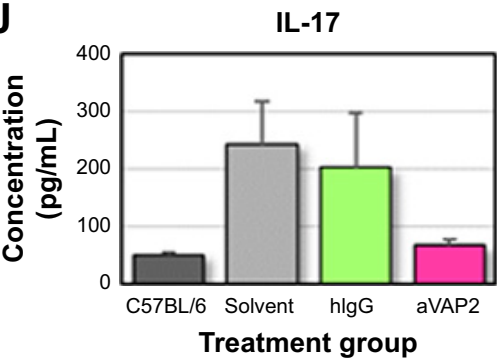

L

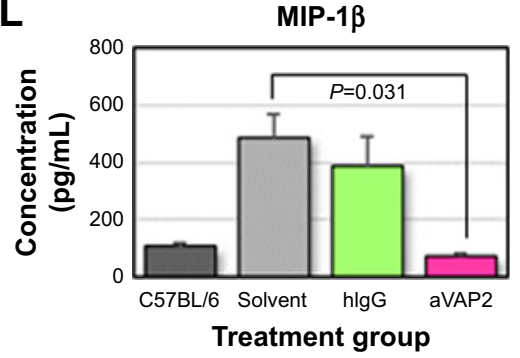

Figure $\mathbf{5}$ Therapeutic effects of aVAP2 in mouse models of MAAV

Notes: Administration of the aVAP2 to SCG/Kj model mice was therapeutic for crescent formation, serum biomarkers of MPO-ANCA, anti-moesin antibodies, and cytokines/chemokines: Glomerular crescent formation rates (\%) in kidneys (A). Microscopic observations of kidneys treated with aVAP2 (B), solvent as a solvent control (C), and hlgG as an immunoglobulin control (D). Serum levels of MPO-ANCA (E), anti-moesin antibody (F), TNF- $\alpha$ (G), IL-I $\beta$ (H), IL-5 (I), IL-I7 (J), IFN- $\gamma$ (K), and MIP-I $\beta$ (L). Bar: $100 \mu \mathrm{m}$.

Abbreviations: aVAP2, anti-VAP2 polyclonal antibodies; IFN, interferon; IL, interleukin; MAAV, MPO-ANCA-associated vasculitis; MIP, macrophage inflammatory protein; MPO-ANCA, myeloperoxidase anti-neutrophil cytoplasmic autoantibodies; TNF- $\alpha$, tumor necrosis factor- $\alpha$.

Structural modification of therapeutic antibodies from their complete forms of immunoglobulins to target-binding antibody fragments may be a major step in the development of antibody drugs. Studies have increasingly focused on the $\mathrm{ScFv}$ region only, which binds antigen(s), especially for cancer treatment and immunotherapy. ${ }^{22,23}$ For example, the CTLA-4 antibody $\mathrm{ScFv}$ is projected to be an effective new antibody-type drug. ${ }^{24}$
We not only isolated a therapeutic antibody fragment clone with therapeutic effects on a mouse MAAV vasculitis model, but also identified its VAP2 target antigen molecule. Furthermore, the VasSF (URq01 clone) amino acid sequence showed high homology with the H-chain $\mathrm{VH}$ region of a mouse monoclonal antibody against VAP2 (Accession No NP_001634). The sequence was not found in any registered human gene sequences, including that of infliximab ${ }^{25}$ or 
rituximab. ${ }^{26}$ Therefore, VasSF may be a therapeutic drug specific for MAAV and would likely replace the currently used nonspecific antibody therapies. Furthermore, VasSF may prevent some severe inflammatory diseases, such as infectious diseases, as VasSF was effective in decreasing inflammatory markers, such as cytokines/chemokines, that are elevated in MAAV model mice.

In addition, VasSF may have applications as a partial substitute for IVIg, which is also used to treat vasculitis. ${ }^{7-9}$ Several hypotheses support this idea. The first is that many kinds of antibodies contained in immunoglobulin preparations, including antibodies against unknown antigens, exert their pharmacological effects by targeting molecules such as VAP2. The second hypothesis is that its effect is on MPO-ANCA autoantibodies to MPO of severe vasculitis, among the many kinds of antibodies. In particular, many kinds of MPO-ANCAs have a wide range of epitopes that exert pharmacological effects. ${ }^{27,28}$ Alternatively, the pharmacological action of VasSF may be against an autoantibody to moesin. ${ }^{29-31}$

Notably, however, the VasSF target antigen, VAP2, associates with AP1 to form high-density lipoprotein (HDL), which has anti-inflammatory action. ${ }^{32}$ It is known that AP1 and AP2 in HDL undergo a structural change due to the oxidative action of $\mathrm{HOCl}$ produced by MPO released from neutrophils. ${ }^{32-35}$ The $\mathrm{HOCl}$ facilitates formation of the VAP2AP1 heterodimer in HDL and decreases its anti-inflammatory activity. These molecular interactions suggest that VasSF might be therapeutically effective not only in vasculitis, but also in cardiovascular diseases.

\section{Conclusion}

The schematic in Figure 6 describes the mechanism of action as follows: Moesin is expressed on endothelial cells and neutrophils from an infection and inflammation. MPO-ANCA binds MPO exposed on the surface of activated neutrophils expressing MPO and moesin. ${ }^{17,18,29-31,36}$ AP1 in HDL plays a central role in reverse cholesterol transport to maintain blood vessel function. Moreover, a moesin-like protein, a glycosylphosphatidylinositol anchor, binds to HDL/AP1 and specifically promotes cholesterol efflux. ${ }^{37}$ This observation suggests that the anti-moesin antibody may block the binding of HDL/AP1 to suppress cholesterol efflux, resulting in damage to vessels. This would be a vicious cycle: antimoesin-MPO-ANCA attaches to MPO on neutrophils, $\mathrm{HOCl}$ is produced, which damages endothelial cells and triggers the formation of VAP2-AP1 heterodimers, which represses the anti-inflammatory activity of HDL. Vascular injury is known

\section{Neutralization of heterodimers of AP1 and VAP2 by VasSF}

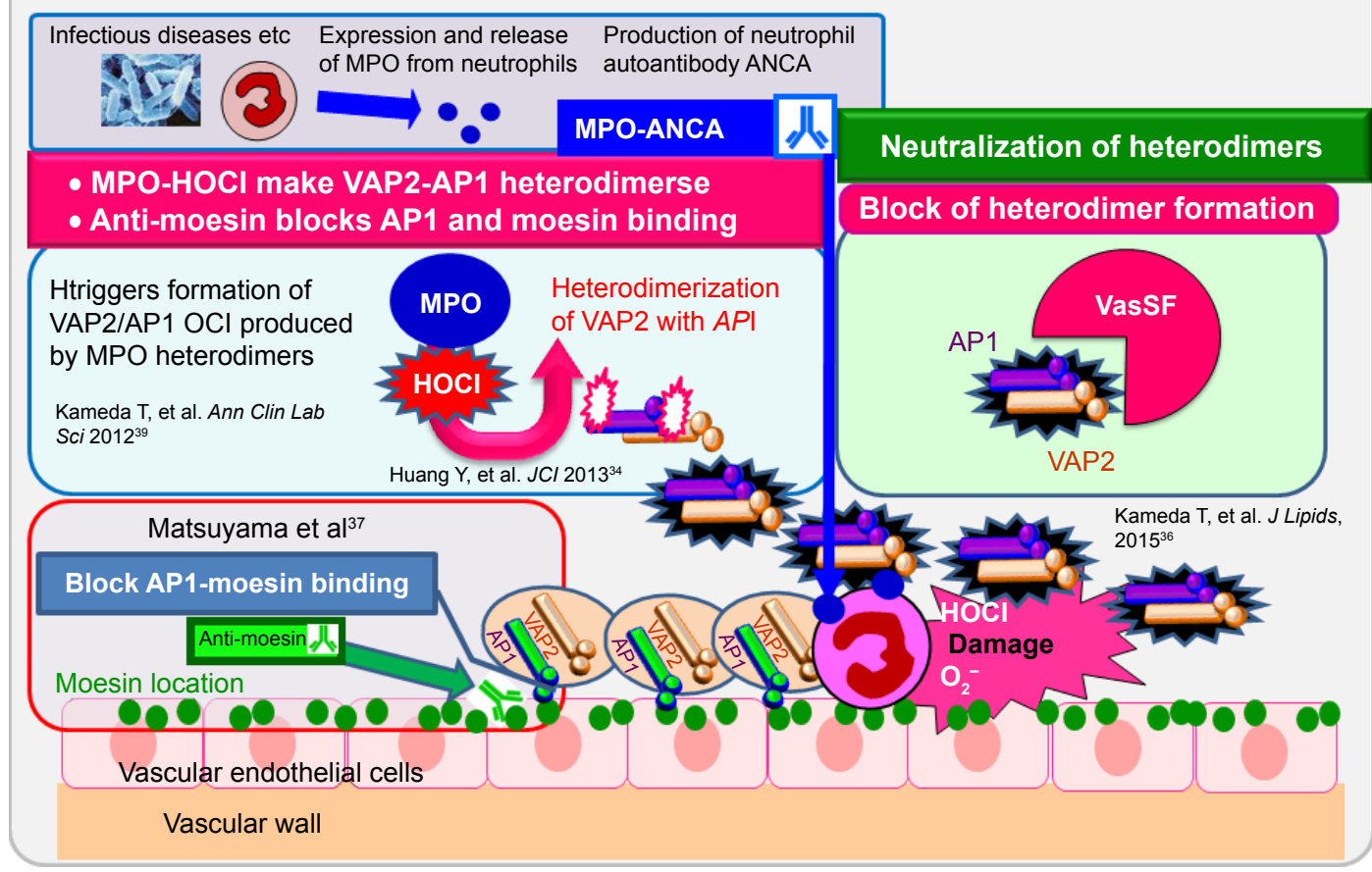

Figure 6 Schematic diagram for effective treatment with VasSF. ${ }^{34,36,37,39}$

Abbreviations: VasSF, vasculitis-associated ScFv; VAP2, vasculitis associated apolipoprotein A2; API, apolipoprotein AI. 
to trigger the formation of heterodimers due to an imbalance between AP1 and AP2 in HDL. ${ }^{38}$ This may result in damage to endothelial cells. Adding the anti-VAP2 antibody fragments, VasSF, might recover MAAV by suppressing this heterodimer formation in peripheral blood.

\section{Acknowledgments}

This study was supported, in part, by a grant from the Gamma-globulin Project from the Japan Science and Technology Agency and the Japan Agency for Medical Research and Development in Japan. We thank Drs Toshiko Ito-Ihara and Wako Yumura for medical advice, Ms Hisae Onodera and Ms Yuko Okada of A-CLIP Institute and Ms Kaoru Tosaka and Ms Haruko Haisa of Teikyo University for their documentation.

\section{Disclosure}

The authors report no conflicts of interest in this work.

\section{References}

1. Alba MA, Jennette JC, Falk RJ. Pathogenesis of ANCA-associated pulmonary vasculitis. Semin Respir Crit Care Med. 2018;39(4):413-424.

2. Laurino S, Chaudhry A, Booth A, Conte G, Jayne D. Prospective study of TNF blockade with adalimumab in ANCA-associated systemic vasculitis with renal involvement. Nephrol Dial Transplant. 2010;25(10): 3307-3314.

3. Yates M, Watts RA, Bajema IM, et al. EULAR/ERA-EDTA recommendations for the management of ANCA-associated vasculitis. Ann Rheum Dis. 2016;75(9):1583-1594.

4. Shah S, Hruskova Z, Segelmark M, et al. Treatment of severe renal disease in ANCA positive and negative small vessel vasculitis with rituximab. Am J Nephrol. 2015;41(4-5):296-301.

5. Shanehbandi D, Majidi J, Kazemi T, Baradaran B, Aghebati-Maleki L. Cloning and molecular characterization of the cDNAs encoding the variable regions of an anti-CD20 monoclonal antibody. Hum Antibodies. 2017;26(1):1-6.

6. Selmi C, Generali E, Massarotti M, Bianchi G, Sciré CA. New treatments for inflammatory rheumatic disease. Immunol Res. 2014;60(2-3): 277-288.

7. Ito-Ihara T, Ono T, Nogaki F, et al. Clinical efficacy of intravenous immunoglobulin for patients with MPO-ANCA-associated rapidly progressive glomerulonephritis. Nephron Clin Pract. 2006;102(1):c35-c42.

8. Jayne DR, Chapel H, Adu D, et al. Intravenous immunoglobulin for ANCA-associated systemic vasculitis with persistent disease activity. QJM. 2000;93(7):433-439.

9. Gopaluni S, Jayne D. Clinical trials in vasculitis. Curr Treatm Opt Rheumatol. 2016;2(2):161-177.

10. Nagelkerke SQ, Kuijpers TW. Immunomodulation by IVIg and the role of Fc-Gamma receptors: classic mechanisms of action after all? Front Immunol. 2014;5(8232):674.

11. Florey O, Haskard DO. Sphingosine 1-phosphate enhances Fc gamma receptor-mediated neutrophil activation and recruitment under flow conditions. J Immunol. 2009;183(4):2330-2336.

12. van Timmeren MM, van der Veen BS, Stegeman CA, et al. IgG glycan hydrolysis attenuates ANCA-mediated glomerulonephritis. J Am Soc Nephrol. 2010;21(7):1103-1114.

13. Kameoka Y, Koura M, Matsuda J, et al. Establishment of a library having 204 effective clones of recombinant single chain fragment of variable region $(\mathrm{hScFv})$ of IgG for vasculitis treatment. ADC Lett Infect Dis Control. 2017;4(2):44-47.
14. Kinjoh K, Kyogoku M, Good RA. Genetic selection for crescent formation yields mouse strain with rapidly progressive glomerulonephritis and small vessel vasculitis. Proc Natl Acad Sci US A. 1993;90(8):3413-3417.

15. Feigl F, Anger V. Eine Tüpfelreaktion Zum Nachweis von nativem Eiweiß [A spotting reaction to detect native proteins]. Microchim Acta. 1937;2:107-110. German.

16. Hurst JL, Beynon RJ, Armstrong SD, et al. Molecular heterogeneity in major urinary proteins of Mus musculus subspecies: potential candidates involved in speciation. Sci Rep. 2017;7(1):44992.

17. Suzuki K, Nagao T, Itabashi M, et al. A novel autoantibody against moesin in the serum of patients with MPO-ANCA-associated vasculitis. Nephrol Dial Transplant. 2014;29(6):1168-1177.

18. Bajema IM, Bruijn JA, Casian A, et al. The European Vasculitis Society 2016 Meeting report. Kidney Int Rep. 2017;2(6):1018-1031.

19. Mohan N, Edwards ET, Cupps TR, et al. Leukocytoclastic vasculitis associated with tumor necrosis factor-alpha blocking agents. J Rheumatol. 2004;31(10):1955-1958.

20. Stone JH, Merkel PA, Spiera R, et al. Rituximab versus cyclophosphamide for ANCA-associated vasculitis. N Engl J Med. 2010;363(3): 221-232.

21. Jones RB, Furuta S, Tervaert JW, et al. Rituximab versus cyclophosphamide in ANCA-associated renal vasculitis: 2-year results of a randomised trial. Ann Rheum Dis. 2015;74(6):1178-1182.

22. Shepard HM, Phillips GL, D Thanos C, Feldmann M. Developments in therapy with monoclonal antibodies and related proteins. Clin Med. 2017;17(3):220-232.

23. Bonnard T, Tennant Z, Niego B, et al. Novel thrombolytic drug based on thrombin cleavable microplasminogen coupled to a single-chain antibody specific for activated GPIIb/IIIa. J Am Heart Assoc. 2017;6(2):e004535.

24. Jin H, Li C, Li D, et al. Construction and characterization of a CTLA4-targeted scFv-melittin fusion protein as a potential immunosuppressive agent for organ transplant. Cell Biochem Biophys. 2013;67(3):1067-1074.

25. Scallon BJ, Moore MA, Trinh H, Knight DM, Ghrayeb J. Chimeric antiTNF-alpha monoclonal antibody cA2 binds recombinant transmembrane TNF-alpha and activates immune effector functions. Cytokine. 1995;7(3):251-259.

26. Davis TA, Czerwinski DK, Levy R. Therapy of B-cell lymphoma with anti-CD20 antibodies can result in the loss of CD20 antigen expression. Clin Cancer Res. 1999;5(3):611-615.

27. Gou SJ, Xu PC, Chen M, Zhao MH. Epitope analysis of antimyeloperoxidase antibodies in patients with ANCA-associated vasculitis. PLoS One. 2013;8(4):e60530.

28. Tomizawa K, Nagao T, Kusunoki R, et al. Reduction of MPO-ANCA epitopes in SCG/Kj mice by 15-deoxyspergualin treatment restricted by IgG2b associated with crescentic glomerulonephritis. Rheumatology. 2010;49(7):1245-1256.

29. Kelsey R. Vasculitis: epitope specificity responsible for MPO-ANCA pathogenicity. Nat Rev Nephrol. 2013;9(6):310.

30. Okano T, Takeuchi S, Soma Y, et al. Presence of anti-phosphatidylserineprothrombin complex antibodies and anti-moesin antibodies in patients with polyarteritisnodosa. J Dermatol. 2017;44(1):18-22.

31. Carney EF. Vasculitis: potential role of an anti-moesin autoantibody in MPO-AAV. Nat Rev Nephrol. 2014;10(2):65.

32. Paiva-Lopes MJ, Delgado Alves J. Psoriasis-associated vascular disease: the role of HDL. J Biomed Sci. 2017;24(1):73.

33. Hadfield KA, Pattison DI, Brown BE, et al. Myeloperoxidase-derived oxidants modify apolipoprotein A-I and generate dysfunctional highdensity lipoproteins: comparison of hypothiocyanous acid (HOSCN) with hypochlorous acid (HOCl). Biochem J. 2013;449(2):531-542.

34. Huang Y, Wu Z, Riwanto M, et al. Myeloperoxidase, paraoxonase-1, and HDL form a functional ternary complex. J Clin Invest. 2013;123(9): 3815-3828.

35. Huang Y, Didonato JA, Levison BS, et al. An abundant dysfunctional apolipoprotein A1 in human atheroma. Nat Med. 2014;20(2):193-203.

36. Kameda T, Ohkawa R, Yano K, et al. Effects of myeloperoxidaseinduced oxidation on antiatherogenic functions of high-density lipoprotein. J Lipids. 2015;2015(9):1-8. 
37. Matsuyama A, Sakai N, Hiraoka H, Hirano K, Yamashita S. Cell surfaceexpressed moesin-like HDL/apoA-I binding protein promotes cholesterol efflux from human macrophages. J Lipid Res. 2006;47(1):78-86.

38. Shao B, Pennathur S, Heinecke JW. Myeloperoxidase targets apolipoprotein A-I, the major high density lipoprotein protein, for sitespecific oxidation in human atherosclerotic lesions. J Biol Chem. 2012; 287(9):6375-6386
39. Kameda T, Usami Y, Shimada S, et al. Determination of myeloperoxidase-induced apoAI-apoAII heterodimers in high-density lipoprotein. Ann Clin Lab Sci. 2012;42(4):384-391. 


\section{Supplementary materials}

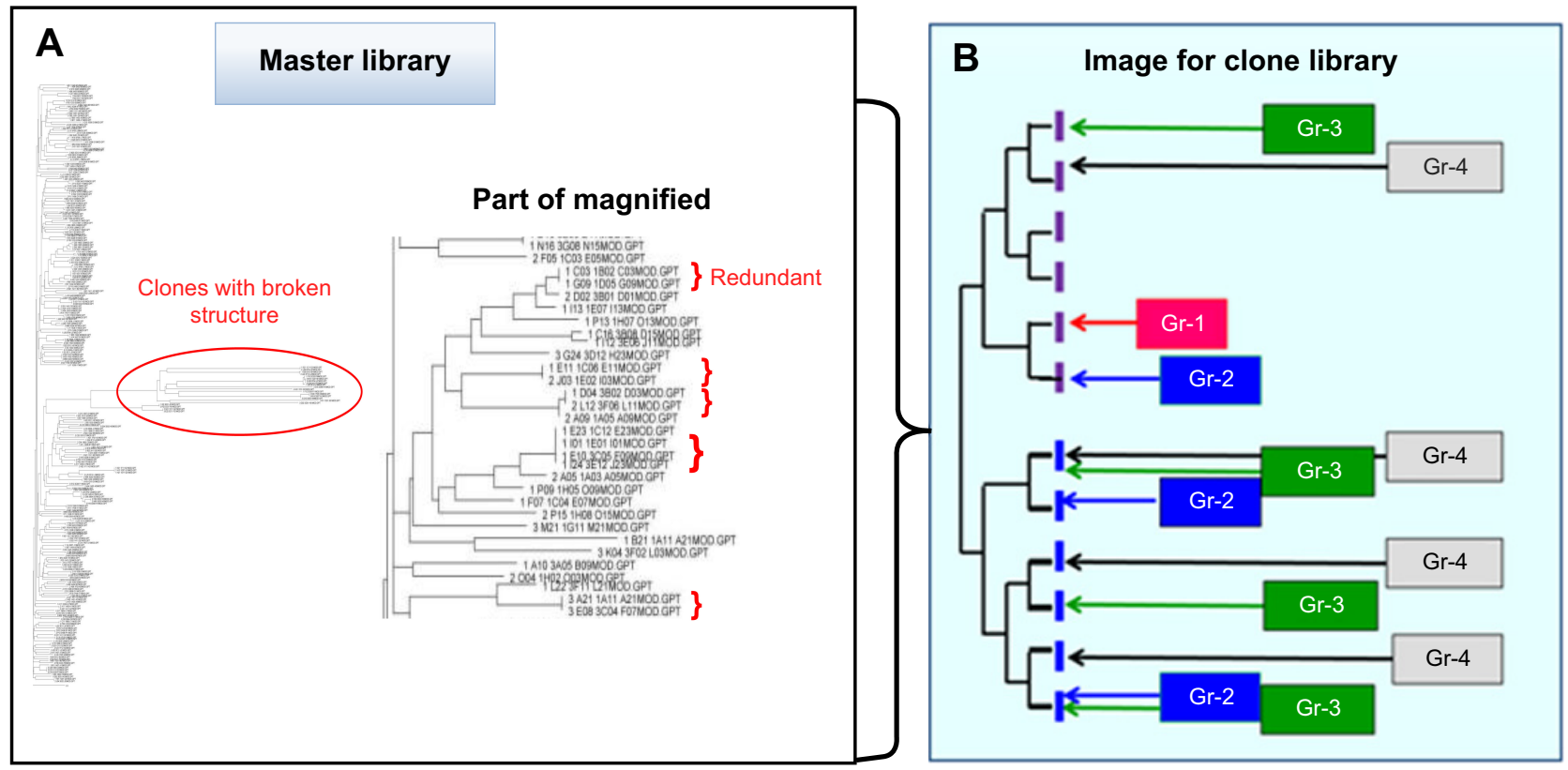

Figure SI Plasmid preparation for hScFv from the 204-clone hScFv library.

Notes: Part of the phylogenetic tree of hScF clones in our library (A). Schematic display of clones selected from our hScFv library (B).

Abbreviation: hScFv, human single chain $\mathrm{Fv}$ region.

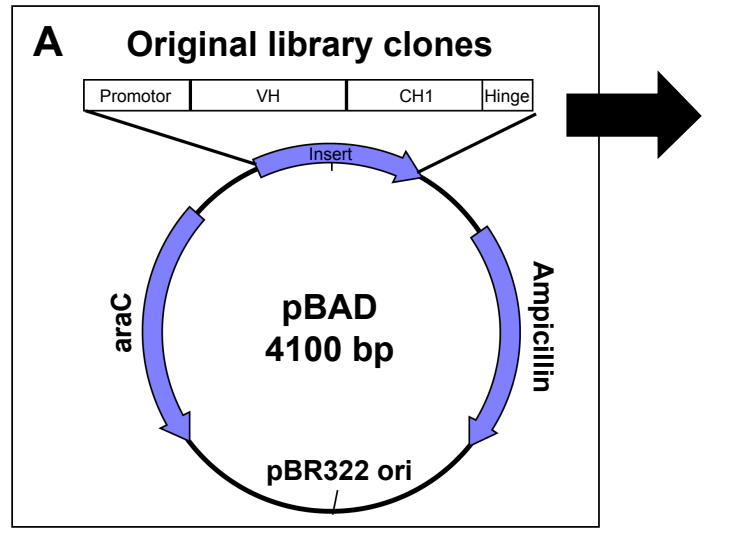

B

Selected clones fragment

Optimization of expression sequence

for Escherichia coli expression

Artificial construction of optimized coding fragment
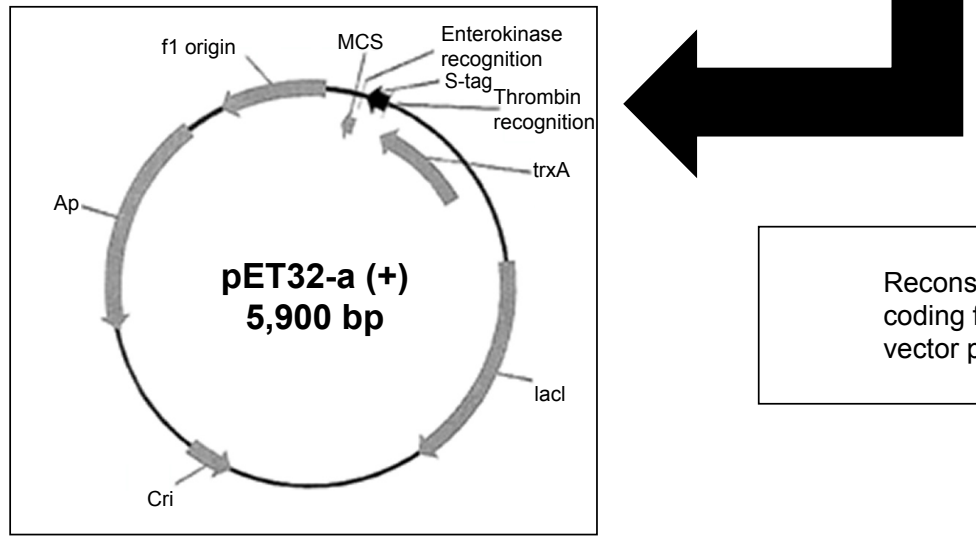

Reconstruction of optimized coding fragment into expression vector $\mathrm{pET} 32$

Figure S2 (Continued) 
C

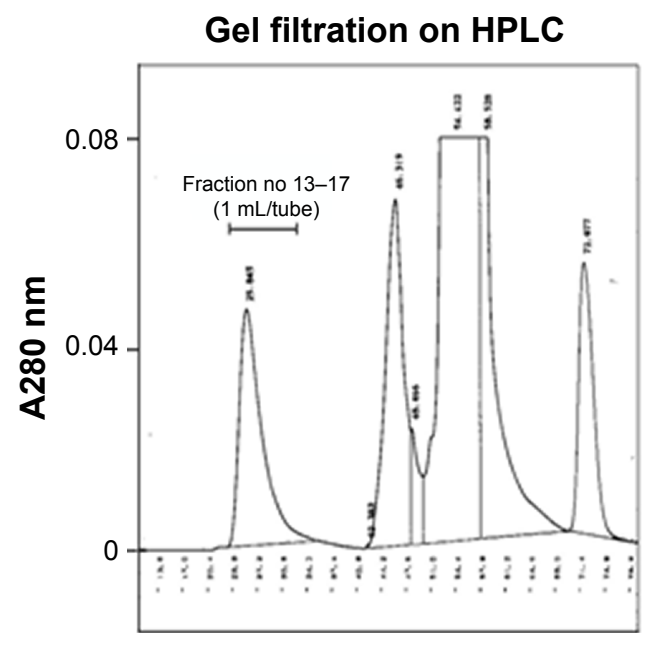

D

\section{CBB staining}

Fraction no

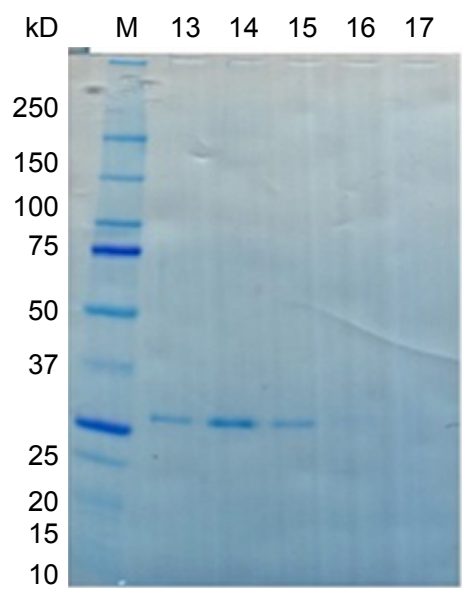

E

\section{Western blot anti-human IgG Fab2}

Fraction no

M $13 \quad 14 \quad 15 \quad 16 \quad 17$

Rentention time (minutes)

Figure S2 Plasmid preparation for hScFv and the purification procedures.

Notes: The original hScFv library was constructed in the pBAD expression vector (A). The selected clones were optimized for Escherichia coli expression and inserted in pET32-a (B). Gel filtration separation profile of hScFv (C). CBB stain of isolated hScFV on SDS-PAGE (D). Western blot analysis of hScFv by anti-human Fab2 antibody (E). Abbreviation: hScFv, human single-chain Fv regions.
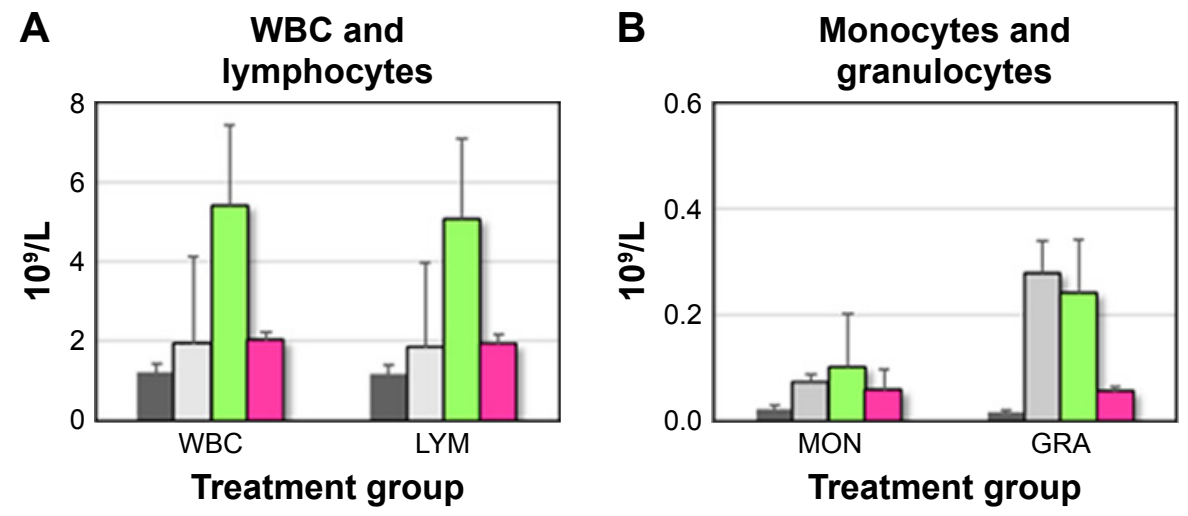

C57BL/6 $\square$ Solvent $\square$ hlgG $\square$ aVAP2

Figure S3 Blood cell counts.

Notes: Counts of WBC, LYM, MON, and GRA in peripheral blood are compared among healthy control C57BL/6, solvent, hlgG-treated, and aVAP2-treated mice in panels ( $\mathbf{A}$ and $\mathbf{B}$ ).

Abbreviations: aVAP2, anti-VAP2 polyclonal antibodies; GRA, granulocytes; LYM, lymphocytes; MON, monocytes; WBC, white blood cells. 
A Rq01_1E10_3C05_F09.gpt AF178457.gpt AF178455.gpt U29146.gpt

Rq01_1E10_3C05_F09.gpt AF178 $457 . \overline{g p t}$

AF178455.gpt U29146.gpt

Rq01_1E10_3C05_F09.gpt AF178 457 .gpt AF178455.gpt U29146.gpt

Rq01 1E10 3C05 F09.gpt AF178457.gpt AF178455.gpt U29146.gpt

Rq01 1E10 3C05 F09.gpt AF178 $457 . \overline{g p t}$ AF178455.gpt U29146.gpt

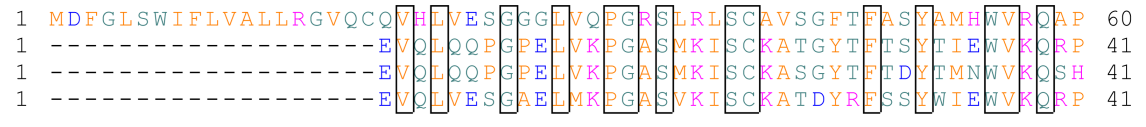

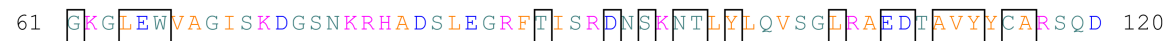
42 GHGEWIGRVNPNSGTTKYNQNEGKAP IADSSNTA MQLLSETEDSAVY CARS-- 99

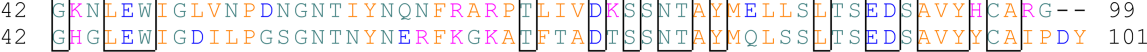

121 PTDEDWLSEHWGQGTLTVSSASTKGPSVEPLAPSRSTSETAALGCLVKDYFPEVT 180 100 - YGYAPGFPS-WGQGTLVTVSAAKTTPPSVYPLAPGCGDTTGSSVTSGCLVKGYFPEPVT 157 100 - YGSSYGFAY-WGQGTLVTVSA

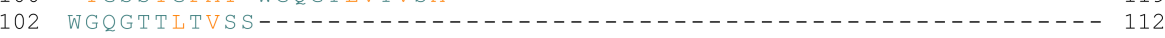

181 VSWNSGATSGVHTFPAVLSSGIYLSSVVTVPSSNEGTTYTCNVDHKPSNTKVDTV 240 158 VTWNSGSISSSVOTFPATIOS-GTYTMSSSVTVPSSTWPSOTVTCSVAHPASSTTVDKKT 216

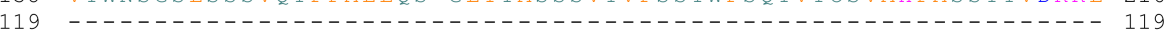
112 - - - - - - - - - - - - - - - - - - - - - - - - - - - - - - - - - - - - 112

241 APPVAGPSVELFPRKRDTHHHHHH

217 EPSGPISTINPCPPC- - - - - - - 231

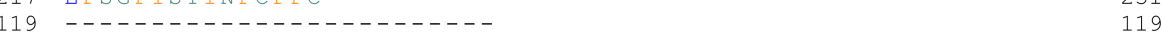

112

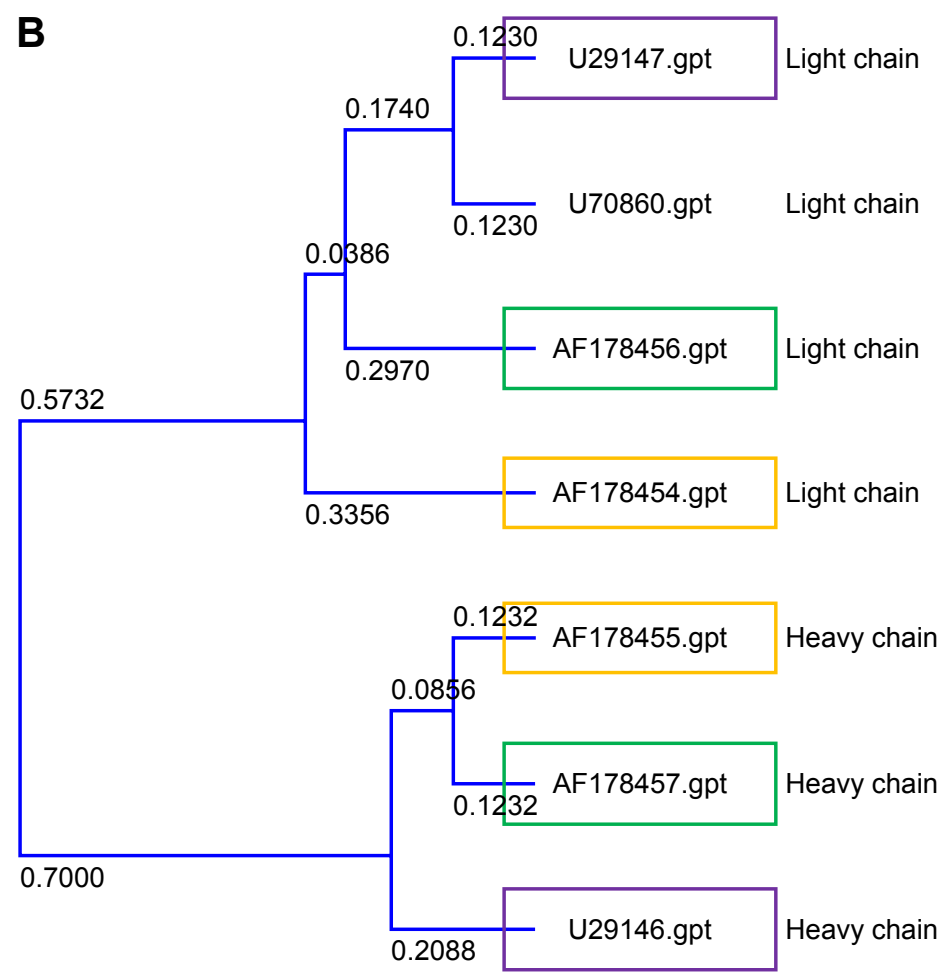

Figure S4 Alignment of amino acid sequence of the variable region among anti-VAP2.

Notes: Alignment of amino acid sequence of the variable regions among anti-apolipoprotein monoclonal antibodies and URq0I (A). Phylogenic analysis of amino acid sequence of the registered variable region of anti-VAP2 monoclonal antibodies (B).

\section{Publish your work in this journal}

Drug Design, Development and Therapy is an international, peerreviewed open-access journal that spans the spectrum of drug design and development through to clinical applications. Clinical outcomes, patient safety, and programs for the development and effective, safe, and sustained use of medicines are the features of the journal, which has also been accepted for indexing on PubMed Central. The manuscript management system is completely online and includes a very quick and fair peer-review system, which is all easy to use. Visit http://www.dovepress.com/testimonials.php to read real quotes from published authors. 